\title{
How district health authorities organise cervical screening
}

\author{
Andrea Elkind, Anne Eardley, Rebecca Thompson, Alwyn Smith
}

\begin{abstract}
Objectives-To examine how district health authorities organised cervical screening with respect to Department of Health guidelines and to determine their assessment of the problems encountered.

Design-Postal questionnaire sent to all 190 district health authorities in England in 1989.

Participants-190 District health authorities in England.

Main outcome measures-Population coverage of screening, quality of smear testing, and follow up of abdominal test results in comparison with national guidelines for district cervical screening services, and problems encountered by districts.

Results-Replies were received from $178(94 \%)$ of districts, in 143 of which the person named as responsible for cervical screening contributed. All districts implemented a computer managed scheme, 150 by the target date of 31 March 1988, but not all of these conformed with the guidelines. At the time of the survey only just over half called women in the target age group of $20-64$ and only $70 \%$ expected to meet the target date of 13 March 1993 for completing the call. Considerable variation was evident among the schemes with regard to how they dealt with issues related to population coverage, quality of testing, and follow up of abnormal results. The problems most commonly identified by the districts $(n=174)$ were laboratory workload $(107,61 \%)$, computer software $(104,60 \%)$, availability of resources $(78,45 \%)$, non-attendance $(77,44 \%)$, rate of opportunistic screening $(62,36 \%)$, and investigation and treatment $(60,34 \%)$.

Conclusions-Current practice in running cervical screening schemes needs to be examined to determine the extent to which it contributes to the goal of reducing mortality from cervical cancer.
\end{abstract}

\section{Introduction}

In the United Kingdom, as in most other countries, cervical screening has failed to reduce mortality from cervical cancer to the extent reported from some of the Nordic countries. ${ }^{1}$ Perhaps the most important reason for the relative failure has been organisational

TABLE I-Districts following guidelines in circular about imple menting call and recall for cervical screening

\begin{tabular}{lr}
\hline & No $(\%)$ \\
\hline Implementing a cervical screening scheme & $178(100)$ \\
Using a computerised database & $178(100)$ \\
Using family practitioner committee computer & $174(98)$ \\
Using Exeter software & $169(95)$ \\
Implementing both call and recall & $171(96)$ \\
Recall at least five yearly & $178(100)$ \\
Calling all women aged 20-64 by 31 March 1993 & $124(70)$ \\
Issuing prior notification list & $160(90)$ \\
Offering choice of general practitioner or clinic & $151(86)^{\star}$ \\
Including leaflet with invitation & $113(65)^{\star}$ \\
Following up non-attenders & $177(99)$ \\
\hline ॠ175 Responders.
\end{tabular}

$\star 175$ Responders. deficiencies, but poor quality testing and inadequate follow up of abnormal test results have also contributed..$^{2-4}$ In an attempt to achieve better results, the Department of Health and Social Security in 1985 made district health authorities responsible for implementing computer managed call and recall schemes to invite women to undergo cervical screening and in 1988 issued a circular $(\mathrm{HC}(88) \mathrm{l})$ that gave detailed guidelines of what was required from a district cervical screening service. ${ }^{6}$ The objective of the service was defined as the reduction of mortality from cervical cancer. In this paper we describe a study commissioned by the Department of Health to examine the implementation of the circular and to identify the views of the districts of the problems encountered.

\section{Methods}

In 1989 we sent a postal questionnaire to "the named individual," specified in the circular responsible for the organisation and effectiveness of cancer screening in the 190 district health authorities in England. The questionnaire sought to assess the extent to which the principal guidelines of the circular had been observed and to obtain the districts' own assessment of the difficulties encountered. After a postal reminder and further telephone follow up 178 districts replied, a response rate of $94 \%$. Some 143 districts indicated that the "named individual" had at least some part in completing the questionnaire, and most of those were public health physicians. The results are presented as a percentage of the districts replying to each question, which in some cases were fewer than 178.

\section{Results}

POPULATION COVERAGE

Table I indicates that most districts implemented a scheme along the broad lines suggested in the circular; $150(84 \%)$ had done so by the target date of 31 March 1988. About half the districts $(n=88)$ have a five year recall interval, 52 used the three year interval recommended by the Intercollegiate Working Party on Cervical Cytology Screening, ${ }^{7}$ and 38 combined the two, usually calling younger women, aged below 35, more frequently. Only just over half the districts, however, were calling all women in the target age group of 20-64 at the time of the survey, and only seven in 10 districts expected to meet the target date of 31 March 1993 for completing the call of this group. A further 33 expected to have done so by the end of 1994 , but 11 gave no date; 10 districts did not intend to call women in the full age range, and of these, six planned to exclude some women aged 35-64, despite the emphasis placed on targeting older unscreened women in the circular.

Most districts issue a prior notification list of eligible women to all practices, providing the opportunity for amendment before issuing invitations and usually
Correspondence to:

Dr Eardley.

BrMed f 1990;301:915-8 
allowing three to four weeks for this. In four districts, however, women were not invited if the prior notification list had not been returned by the practice, thus reducing the chance of achieving maximum population coverage. Letters of invitation were produced by the family practitioner committee in eight out of 10 districts. In the 82 districts in which some general practitioners did not take smears alternative arrangements were made to invite their patients to district clinics. Even when the general practitioner took the smears, however, the letter was not necessarily signed by him or her: in 62 districts it was signed by a representative of an institution, such as a family practitioner committee administrator, director of public health, or pathologist, who is likely to be unknown to the woman.

Table I shows that most districts offer a choice of venue for the test. Only about half (98), however, gave information about the location of clinics. Even when a clinic was the only option, only seven out of 10 districts supplied a list of clinics or a central contact number. An analysis of the invitation letters themselves showed that less than a tenth referred to the possibility of a woman taking the smear as suggested in the circular. ${ }^{8}$

\section{QUALITY OF TESTING}

Table II shows that a substantial proportion of districts were not following the guidelines suggested for improving the quality of taking smears. In relation to processing smears, answers were sought about the main screening laboratory used. In the 48 districts where more than one laboratory was in use the task of implementing recommendations is likely to be more difficult. Most districts processed smears on average

TABLE II-Districts following the guidelines in circular about improving the quality of smears and laboratory services

\begin{tabular}{lr}
\hline & No $(\%)$ \\
\hline $\begin{array}{l}\text { Aylesbury spatula to be available }(\mathrm{n}=176) \\
\text { Information to those taking smears about } \\
\text { unsatisfactory smears }(\mathrm{n}=178)\end{array}$ & $116(66)$ \\
Training courses for those taking smears $(\mathrm{n}=168)$ & $54(30)$ \\
National request form to be used $(\mathrm{n}=175)$ & $69(41)$ \\
Processing of smears in one month $(\mathrm{n}=173)$ & $140(80)$ \\
Monitoring backlog of smears at laboratory $(\mathrm{n}=178)$ & $130(75)$ \\
Internal and external quality control $(\mathrm{n}=173)$ & $154(87)$ \\
Computer in laboratory $(\mathrm{n}=178)$ & $90(52)$ \\
Computer link between laboratory and family & $115(65)$ \\
practitioner committee $(\mathrm{n}=178)$ & $67(38)$ \\
Notifying of database of all test results $(\mathrm{n}=177)$ & $131(74)$ \\
\hline
\end{tabular}

within one month, but four took eight weeks or more. Districts usually tried to reduce any backlog by increased staffing (77 districts) or the use of outside agencies (47 districts, including 25 who use private laboratories). Twenty one districts, however, suspended or reduced their call and recall rates or refused to process opportunistic smears taken within the recommended interval.

Although only about half the laboratories had both internal and external quality controls, most of the rest had one system, usually internal, but four reported no quality control at all. In a substantial proportion of districts computer facilities for recording and transferring information about results were not available.

\section{FOLLOW UP}

With regard to providing information about results (table III), in five districts general practitioners were not notified of the result if they had not taken the smear themselves, and in 49 they were neither given information from the database about abnormal smear test results, nor were such results highlighted on the result form. Fewer than half the districts $(70)$ routinely informed women of a negative result by letter, with
TABLE III-Districts following guidelines in circular about informing general practitioners and women about cervical smear test results

No $(\%)$

General practitioners usually to be informed of test results $(n=178)$

Abnormal results to be highlighted on form $(n=177)$

Abnormal results to be highlighted on form $(n=177)$

Database to inform general pract

Women to be sent letter about negative result $(n=167)$

half of these making it the responsibility of the person taking the smear, and 10 leaving it to the woman herself to obtain the information-despite the publicity given to failures of follow up in such circumstances.

In most districts (135) the pathologist always recommended the appropriate follow up for non-negative results, and in the remainder an agreed protocol, as suggested by the circular, existed in all but 14 . Almost all districts had implemented a failsafe system to ensure that appropriate follow up occurred (table IV), but they did not always follow the procedures indicated in the circular.

TABLE IV-Districts following guidelines in circular about failsafe mechanisms

\begin{tabular}{lc}
\hline & No $(\%)$ \\
\hline $\begin{array}{l}\text { Implementing a failsafe system }(n=178) \\
\begin{array}{l}\text { Laboratory is responsible for checking appropriate follow up } \\
\text { has occurred }(n=164)\end{array}\end{array}$ & $166(93)$ \\
$\begin{array}{l}\text { First failsafe action is to make inquiries of the person taking } \\
\text { smear }(n=161)\end{array}$ & $118(72)$ \\
\hline
\end{tabular}

The circular indicates that districts should ensure prompt investigation, treatment, and follow up, but it does not define "prompt." Of those districts that supplied separate information about waiting times for investigation and treatment, $57 \%(70)$ recorded an average wait before referral and investigation of five weeks or more (including 11 with a delay of 13 weeks or more) and $39 \%$ (31) an average wait between investigation and treatment of five weeks or more (including 11 in which women waited 13 weeks or more). As suggested in the circular, colposcopy was available to all women in $93 \%$ of districts and to some women in a further $5 \%$, but two districts did not provide this facility at all. Of these, one indicated that women are occasionally referred outside the district but the other provided no further information.

\section{ASSESSMENT BY DISTRICTS}

Only 22 districts reported being very satisfied with their scheme, but 128 were fairly satisfied. The factors that contributed most to satisfaction were identified as the cooperation of the different agencies concerned, positive involvement of general practitioners, and the commitment and hard work of those participating.

Districts were asked to select from a list the broad problems they had encountered and to describe them in more detail. Table $\mathrm{V}$ indicates the frequency with which problems were selected and the extent to which they were identified as the single most important difficulty encountered. Six problems were of particular significance, being identified in more than a third of the questionnaires. Difficulty with the laboratory workload was the most commonly reported problem (in $62 \%$ of districts) and was considered to be the most important problem in a quarter of districts. The most important element was the shortage of screening staff, partly the result of a lack of funding but more importantly because of difficulties with recruitment and retention. Salaries were unattractive, trained staff in short supply, and new recruits required a lengthy training. Implementing schemes had in some' cases led 
TABLE $\mathrm{v}$-Incidence of problems in cervical screening experienced by districts

\begin{tabular}{lcc}
\hline & $\begin{array}{c}\text { Problem } \\
\text { reported } \\
\text { (174 districts) }\end{array}$ & $\begin{array}{c}\text { Identified as } \\
\text { single most } \\
\text { important } \\
\text { problem } \\
\text { 169 districts) }\end{array}$ \\
Problem & $107(61)$ & $43(25)$ \\
Laboratory workload & $104(60)$ & $24(14)$ \\
Computer software & $78(45)$ & $21(12)$ \\
Availability of resources & $77(44)$ & $18(11)$ \\
Non-attendance & $62(36)$ & $5(3)$ \\
Rate of opportunistic screening & $60(34)$ & $4(2)$ \\
Investigation and treatment & $49(28)$ & $10(6)$ \\
Database & $47(27)$ & $3(2)$ \\
Failsafe mechanism & $44(25)$ & $8(5)$ \\
Obtaining cooperation of general & $43(25)$ & $1(1)$ \\
practitioners & $40(23)$ & $9(5)$ \\
Design of letters and leaflets & $36(21)$ & $3(2)$ \\
Liaison & $25(14)$ & $1(1)$ \\
Prior notification list & $22(13)$ & $8(5)$ \\
Rate of unsatisfactory smears & $20(12)$ & \\
Getting started & $17(10)$ & \\
Computer hardware & & \\
Laboratory quality control & $14(8)$ & $4(2)$ \\
Computer link between laboratory and & $13(8)$ & \\
family practitioner committee & $5(3)$ & $1(1)$ \\
Criteria for call and recall & $6(3)$ & \\
Availability of women staff to take smears & & \\
Other & & \\
\hline
\end{tabular}

to an increase in laboratory workload and to long waiting times for results. The computer software had also posed difficulties (in $60 \%$ of districts, being the most important problem in $14 \%$ ), in particular, the non-availability of the Exeter package and the poor quality of the statistical information provided (at that time). Districts had been unable to monitor their scheme or to identify target groups for special attention. Specific faults identified in the software were the fixed parameters, giving rise to poor quality invitation letters, the deletion of non-attenders from the system, the inability to distinguish tests taken as a result of the scheme and for other reasons, the inability to follow up women with abnormal results, and the lack of failsafe procedures. Since the survey, however, considerable progress has been made with the Exeter package. Many districts (45\%) indicated that resources were generally inadequate whereas others described more specific needs - for example, for clerical staff, cytology screeners, or colposcopic facilities. Costs were sometimes greater than originally estimated, particularly with regard to the computing and family practitioner committee components. As resources had to be found from existing budgets this could lead to underfunding, increased workload, or money being diverted from elsewhere. Poor attendance was regarded as a major problem, particularly in older women, unscreened women, women with high mobility, and women in ethnic minorities, the lower social classes, or inner city populations. Contributory factors were identified as inflexible appointment systems, singlehanded male general practitioners, and the inaccuracy of the family practitioner committee register. These problems were compounded by the poor quality of information available from the software about non-attendance.

Thus it is clear that several problems were interrelated. For example, opportunistic testing of women already screened within the district policy interval added to the burden of already overstretched laboratories. In part the problem manifested itself as local resistance among both women and general practitioners to a five year recall policy, but districts with a three year interval policy also reported difficulties. Investigation and treatment also have resource implications. Colposcopic facilities were often seen as inadequate, giving rise to delays, although some districts reported the allocation of extra funding to meet the increasing demand.

Overall, three broad issues could be identified from the analysis of problems: resources, computing, and communications. Firstly, as already noted, many of the difficulties described were either the result of underfunding or their solution had resource implications - for example, offering training to people who took a high proportion of unsatisfactory smears. Secondly, there were computer related factors, including difficulties in initially setting up the family practitioner committee systems and deficiencies in the hardware as well as the software and in the quality of information in the database. Absence of a computer in the laboratory, lack of a computer link between the database and the laboratory, and delay in updating information were also identified as problems. Thirdly, in a complex system such as cervical screening, with fragmented responsibility for different aspects of the scheme, the issue of communication looms large. Liaison between the district and family practitioner committee on the one hand, and the family practitioner committee and the laboratory on the other, might prove difficult, as might the role of the general practitioner as an independent contractor within a district operated scheme. These relations had implications for the initial implementation of the scheme on a basis satisfactory to all parties and for matters ranging from the design of letters and leaflets to the development of failsafe mechanisms.

\section{Discussion}

The planning, implementation, and operation of a cervical screening programme is a considerable undertaking. It entails several stages, each consisting of numerous procedures and involving many documents, and requires the coordination of several agenciesdistrict, family practitioner committee, general practice, laboratory, and hospital-all of which must provide staff, skills, and resources to fulfil their role in the system and whose interpretation of that role may not always be congruent. At the centre are the women who are the subject of screening, who must be dealt with appropriately at every stage. That some districts have not yet succeeded in achieving the optimal service is not surprising.

The circular gives guidance about the organisation of schemes, but this study indicates that considerable variation exists in the way it has been interpreted. Variety itself is not detrimental to the effectiveness of screening as long as the ultimate objective, the reduction in mortality from cervical cancer, is kept in view. As a way to achieve this objective Pye defined a set of management goals and specified the associated tasks to be performed. ${ }^{9}$ The basis for decision making when implementing and operating schemes must be made explicit and each element of current practice examined to determine whether it leads to or detracts from the achievement of the ultimate aim.

At the same time it is important to recognise the difficulties faced by the districts in implementing schemes, whether these are associated with very specific computer related issues, the more amorphous questions of effective communication in a situation of fragmented responsibility, or the basic problem of finding the necessary resources to underpin the scheme and its ramifications at all levels.

We thank the staff of all the districts who participated in this survey. The study was funded by the Department of Health.

1 Hakama $M$. Trends in the incidence of cervical cancer in the nordic countries. In: Knut M, ed. Trends in cancer incidence. London: Hemisphere, 1982: In: Knut

2 Eardley A, Elkind AK, Spencer B, Hobbs P, Pendleton LL, Haran D. Attendance for cervical screening-whose problem? Soc Sci Med 1985;20: 955-62.

3 Chamberlain J. Reasons that some screening programmes fail to control cervical 
ancer. In: Hakama M, Miller AB, Day NE, eds Screening for cuncer of the ulerine cervix. Lvons: International Agency for Research on Cancer, 1985 161-8. (IARC Scientific Publications No 76.)

4 Chisholm D, Haran D. Cases of invasive cervical cancer in the north west in spite of screening. British fournal of Fumily Planning 1984;289:883-6.

Department of Health and Social Security. Cervical cancer screening. London DHSS, 1985. (DA $(85) 8$.)

6 Department of Health and Social Security. Health services management: cervical cancer screening. London: DHSS, 1988 (HC(88)1.)
7 Intercollegiate Working Party on Cervical Cytology Screening. Report. London: Royal College of Obstetricians and Gynaecologists, 1987.

8 Eardley A, Elkind A, Thompson R. HEA guidelines for a letter to invite women for a smear test: theory and practice. Health Education fournal 1990;49:51-6. 9 Pye M. NHS cervical screening programme: education and training needs of programme managers. Oxford: National Breast Cancer Screening Education Programme, 1989.

\title{
Management of major status epilepticus in adults
}

\author{
M D O'Brien
}

Major status epilepticus in adults is a medical emergency. The patient is often first seen in an accident and emergency department by a doctor who may not have had to deal with this problem before. The associated mortality is around $10 \%$, and convulsive seizures that last longer than two hours may be associated with permanent neurological sequelae. It is important to stop the seizures and then to keep the seizures under control. Seizure activity can nearly always be stopped, at least temporarily, with intravenous diazepam, but it should always be assumed that seizures are likely to start again, and the respite achieved with diazepam should be used to follow the protocol outlined below. Problems arise when these essential steps are not taken until after the fits resume.

(Accepted 13 fune 1990)

\section{Initial management}

(1) Remove any false teeth, establish an airway, and give oxygen by mask at a high flow rate. Assess the patient, verify the diagnosis, and place him or her in the lateral semiprone position.

(2) Diazepam (Diazemuls, $10 \mathrm{mg}$ in $2 \mathrm{ml}$ ) intravenously $0 \cdot 15-0 \cdot 25 \mathrm{mg} / \mathrm{kg}$, usually as a $10 \mathrm{mg}$ bolus followed immediately by a further $10 \mathrm{mg}$ $(2 \mathrm{ml}$ ) over 1-2 minutes. This may be repeated once if necessary. (See note 1.)

(3) Take blood ( $5 \mathrm{ml}$ in a fluoride tube) for measurement of anticonvulsant drugs, alcohol, and sugar concentrations; also measure concentrations of calcium, electrolytes, and urea, obtain a full blood picture, and put a drop of blood on to a test strip (BM stick). Save a blood sample for a drug screen.

(4) If the result on BM stick testing indicates a low blood glucose concentration give $50 \%$ glucose $25 \mathrm{ml}$ intravenously, preferably by catheter and not into a small distal vein.

(5) If alcohol is likely to be a factor give thiamine $100 \mathrm{mg}$ intravenously. If alcohol withdrawal is the cause give chlormethiazole (see (7)).

(6) Phenytoin (250 $\mathrm{mg}$ in $5 \mathrm{ml}$ ) intravenously 15 $\mathrm{mg} / \mathrm{kg}$ no faster than $50 \mathrm{mg} / \mathrm{min}$ by infusion pump or slow intravenous injection. (See note 2.)

Do not leave the patient until seizures have stopped.

If fits continue transfer the patient to the intensive care unit and consult an anaesthetist and a neurologist.

(7) Chlormethiazole $(8 \mathrm{mg} / \mathrm{ml})$ intravenously. Give a loading dose of up to $800 \mathrm{mg}(100 \mathrm{ml})$ over 10 minutes $(10 \mathrm{ml} / \mathrm{min})$, and maintain with $0 \cdot 5-1 \cdot 0$ $\mathrm{ml} / \mathrm{min}(4-8 \mathrm{mg})$.

Department of Neurolog Guy's Hospital, London SE1 5RT

M D O'Brien, FRCP, physician for nervous diseases

BrMed f 1990;301:918 mins. Then give thiopentone $1-3 \mathrm{mg} / \mathrm{kg} / \mathrm{h}$, maintaining a maximum blood thiopentone concentration of $60-100 \mathrm{mg} / \mathrm{l}$. (See note 3.)

A brain function monitor may be useful in determining whether there is seizure activity and the depth of barbiturate anaesthesia.

Notes

(1) Diazemuls is preferred because ordinary diazepam causes phlebitis. A bolus injection of $10 \mathrm{mg}$ may cause respiratory depression and hypotension, which may be pronounced if there is concurrent use of other central nervous system depressant drugs, especially phenobarbitone.

Diazepam must not be given intramuscularly or subcutaneously, added to an intravenous infusion, or given with phenobarbitone unless artificial ventilation is available.

Rectal diazepam (Stesolid rectal tubes), $5 \mathrm{mg}$ or $10 \mathrm{mg}$ in $2.5 \mathrm{ml}$, may be used for the immediate treatment of epilepsy instead of intravenous diazepam.

(2) Phenytoin must not be given intramuscularly or subcutaneously, given by central line, added to a dextrose infusion, or given with any other drug.

Intravenous phenytoin should be monitored with continuous electro-cardiography. If this is not available, it may be safer to use a dilute solution of $250 \mathrm{mg}$ ( $5 \mathrm{ml}$ ) of phenytoin in $250 \mathrm{ml}$ of physiological saline. The dilute solution should be used immediately provided that there is no evidence of precipitation and preferably with an in line filter (dilution of phenytoin is not licenced).

(3) Facilities for measuring blood thiopentone and pentobarbitone concentrations are available in only a limited number of centres, but it is still worth monitoring these concentrations if the patient requires continued treatment with thiopentone over several days. 